\title{
Development and validation of a chromatographic method for quantification of rasagiline in human plasma
}

\author{
Rabiea Bilal $^{1 *}$, Muhammad Usman ${ }^{2}$, Abdul Muqeet Khan ${ }^{3}$, Waqas Latif ${ }^{4}$, \\ Naseem Saud Ahmad ${ }^{5}$, Sualeha Riffat ${ }^{2}$ \\ ${ }^{1}$ Department of Pharmacology, CMH Lahore Medical and Dental College, Abdul Rehman Road, Lahore Cantt, ${ }^{2}$ Institute of \\ Pharmaceutical Sciences, ${ }^{3}$ Quality Operations Laboratory, University of Veterinary and Animal Sciences, ${ }^{4}$ Quality \\ Enhancement Cell, University of Health Sciences, ${ }^{5}$ Department of Pharmacology, Sharif Medical and Dental College, Lahore, \\ Pakistan
}

*For correspondence: Email: docrabiea@gmail.com; Tel: 0092301848757

Sent for review: 11 July 2018

Revised accepted: 24 October 2018

\begin{abstract}
Purpose: To develop a sensitive, reliable and cost-effective bioanalytical method for the pharmacokinetic analysis of rasagiline in human plasma.

Method: Rasagiline was extracted by liquid-liquid extraction method and analyzed by reversed-phase high performance liquid chromatography (HPLC) using a mixture of ammonium acetate ( $p H$ 5.8) and acetonitrile $(55: 45, \mathrm{v} / \mathrm{v})$ as mobile phase at a flow rate of $1 \mathrm{~mL} / \mathrm{min}$. The separation was performed on a Lichrosphere reverse-phase (RP) C18 column $(250 \times 4.6 \mathrm{~mm}, 5 \mu \mathrm{m}$ particle size $)$ at ambient temperature and rasagiline was detected at a wavelength of $265 \mathrm{~nm}$ by ultra-violet UV detection. The method was validated according to European Medicine Agency (EMA) guidelines.

Results: The developed method was linear over a concentration range of $0.5-20 \mu \mathrm{g} / \mathrm{m} /$ with $\mathrm{r} 2 \geq 0.999$ in human plasma. Run time was 10 min with rasagiline peak appearing at 7 min with no interference. Relative recovery and relative standard deviation (RSD) for accuracy and precision were within the acceptable limits prescribed in EMA guidelines. Rasagiline remained stable in human plasma for $24 \mathrm{~h}$ at room temperature, after three freeze and thaw cycles and also for 3 months at $-20^{\circ} \mathrm{C}$.

Conclusion: A simple and reliable method has been successfully developed and validated for the determination of rasagiline concentration in human plasma.
\end{abstract}

Keywords: Rasagiline, Pharmacokinetics, Validation, Parkinson's disease

\begin{abstract}
This is an Open Access article that uses a funding model which does not charge readers or their institutions for access and distributed under the terms of the Creative Commons Attribution License (http://creativecommons.org/licenses/by/4.0) and the Budapest Open Access Initiative (http://www.budapestopenaccessinitiative.org/read), which permit unrestricted use, distribution, and reproduction in any medium, provided the original work is properly credited.
\end{abstract}

Tropical Journal of Pharmaceutical Research is indexed by Science Citation Index (SciSearch), Scopus, International Pharmaceutical Abstract, Chemical Abstracts, Embase, Index Copernicus, EBSCO, African Index Medicus, JournalSeek, Journal Citation Reports/Science Edition, Directory of Open Access Journals (DOAJ), African Journal Online, Bioline International, Open-J-Gate and Pharmacy Abstracts

\section{INTRODUCTION}

Rasagiline mesylate $(\mathrm{RM})$ is chemically designated N-Propargyl-1(R)-aminoindan mesylate and is currently approved as initial monotherapy or adjunct therapy to levodopa for the treatment of idiopathic Parkinson's disease in the United States and Europe [1,2]. Rasagiline improves dopaminergic transmission in Parkinson Disease [3] and is believed to produce its anti-parkinson effect by selectively inhibiting monoamine oxidase B enzyme [4-6].

The oral dose of rasagiline is $1 \mathrm{mg}$ per day. The absorption of rasagiline is not affected by food 
and oral bioavailability is approximately $36 \%$ in humans. After oral administration, it reaches peak plasma concentration in an hour. The volume of distribution and elimination half-life of $\mathrm{RM}$ in humans is $87 \mathrm{~L}$ and 0.6 - $2 \mathrm{~h}$ respectively. $\mathrm{RM}$ is reported to follow linear pharmacokinetics in the dose range of $1-10 \mathrm{mg}$ when administered through the oral route [7]. It undergoes extensive hepatic metabolism by the enzyme CYP1A2 which shows genetic variability in humans (slow, intermediate and fast metabolizers) [8]. The enzyme activity is also influenced by smoking that can change pharmacokinetics of a drug [9].

A few bio-analytical methods have been reported for the quantification of rasagiline in bulk and pharmaceutical dosage form [10]. The quantification of drug in human plasma has been done using expensive and advanced instruments like Liquid Chromatography Tandem Mass spectrophotometer which require many processing steps for sample preparation [7,1113]. A method for estimating rasagiline in different plasma matrices using HPLC with UV detector has been reported with limit of detection (LOD) $150 \mathrm{ng} / \mathrm{mL}$ and limit of quantification (LOQ) $450 \mathrm{ng} / \mathrm{mL}$ however, this method was applied for pharmacokinetic study in rabbits only [12].

Despite available methods, a simple, sensitive and cost effective method using HPLC with UV detection is still required to quantify rasagiline in human plasma for subsequent pharmacokinetic study as it is necessary to study the effects of different factors on rasagilne pharmacokinetics in human. Genetic variations, pathological states, diet and smoking status have been reported to affect the pharmacokinetics of different drugs resulting in impaired responses in patients $[14,15]$. The objective of this study is to develop and validate a reliable \& cost-effective HPLC method for the determination of rasagiline in human plasma for pharmacokinetic studies with the advantage of improved linearity, LOQ, LOD accuracy, precision, recovery and quantification and stability under freeze thaw cycles.

\section{EXPERIMENTAL}

The chemicals and solvents used in this study were analytical and HPLC grade. Acetonitrile, methanol and $10 \mathrm{mM}$ ammonium acetate were bought from Merck Darmstadt, Germany. Rasagiline standard was provided by Searle, Pakistan. The citrated human plasma was obtained from Bioequivalence Study (BeSt) centre, University of Veterinary and Animal Sciences, Lahore, Pakistan.

\section{Sample preparation}

A stock solution of $1 \mathrm{mg} / \mathrm{mL}$ concentration of rasagiline was prepared by dissolving $10 \mathrm{mg}$ of rasagiline standard in $10 \mathrm{~mL}$ of methanol. Six calibration standard solutions were prepared by serial dilution. The final concentrations in standard solutions were $0.5,1.0,5.0,10.0$ and $20.0 \mu \mathrm{g} / \mathrm{mL}$. The quality control (QC) samples were prepared from a separate stock solution of $1 \mathrm{mg} / \mathrm{mL}$ concentration. The lower quality control (LQC), median quality control (MQC and higher quality control (HQC) samples were prepared as $0.7,6.0$ and $15.0 \mu \mathrm{g} / \mathrm{mL}$, respectively.

\section{Extraction}

The extraction of rasagiline from plasma samples was performed by mixing $600 \mu \mathrm{L}$ of plasma with $900 \mu \mathrm{L}$ acetonitrile in polypropylene tubes. The tubes were vortex mixed for $2 \mathrm{~min}$ and centrifuged at $400 \mathrm{~g}$ for $10 \mathrm{~min}$. The supernatant was transferred to another polypropylene tube and evaporated to dryness at $37^{\circ} \mathrm{C}$. The residue was reconstituted in $600 \mu \mathrm{L}$ of mobile phase and $80 \mu \mathrm{L}$ was injected into HPLC for analysis.

\section{Chromatographic conditions}

The HPLC system comprised of an LC-20AT VP pump, an SIL-20AC HT auto-sampler, UV detector SPD-M20A, CTO 20 AC and CBM 20A (Shimadzu, Germany). A mixture of $10 \mathrm{mM}$ ammonium acetate $\left(\mathrm{NH}_{4} \mathrm{CH}_{3} \mathrm{CO}_{2}\right)$ with $\mathrm{pH}$ adjusted to 5.8 and acetonitrile $(55: 45$, v/v) was used as mobile phase. The buffer was filtered through a $0.22 \mu \mathrm{m}$ (Millipore) before mixing with acetonitrile. The separation was performed on Lichrosphere C18 column (250 x $4.6 \mathrm{~mm}, 5 \mu \mathrm{m}$ particle size) equipped with a guard column of the same packing material at ambient temperature. The mobile phase was pumped at a flow rate of $1 \mathrm{~mL} / \mathrm{min}$ and rasagiline was detected at $265 \mathrm{~nm}$ wavelength using a UV detector.

\section{Validation}

The method was validated in accordance with the standards of good laboratory practice (GLP). Method validation was performed following EMA guidelines for Bioanalytical method validation [16]. Method validation included selectivity, linearity, accuracy, precision (intra- and interday), stability and recovery.

\section{Selectivity}

Selectivity was evaluated by comparing the chromatogram of plasma samples spiked with 
20.0 and $0.5 \mu \mathrm{g} / \mathrm{mL}$ concentrations of rasagiline with drug free plasma samples prepared by same method as used for extraction of rasagiline in spiked samples.

\section{Linearity}

Five calibration curves were plotted each comprising six calibration standards with concentrations ranging from $0.5-20.0 \mu \mathrm{g} / \mathrm{mL}$. The peak area of each calibration standard was plotted against the corresponding concentration of rasagiline to obtain the respective calibration curve and coefficient of determination as an evidence of linearity of each graph. The concentration of each calibration standard was back calculated from same calibration curve in order to determine the limit of quantification (LOQ). The lowest level in calibration curve with back calculated concentration accepted for accuracy and precision was considered as LOQ.

\section{Accuracy and precision}

The quality control samples $(\mathrm{n}=6)$ of LQC $(0.7 \mu \mathrm{g} / \mathrm{mL}), \quad M Q C \quad(6.0 \mu \mathrm{g} / \mathrm{mL})$, and HQC $(15.0 \mu \mathrm{g} / \mathrm{mL})$ were prepared and analyzed for evaluation of with-in run accuracy and precision. The concentration of rasagiline in each QC sample was determined through a simultaneously obtained calibration curve. To evaluate between run accuracy and precision, quality control samples of LQC, MQC and HQC were analyzed on six different days for the quantification of rasagiline concentrations using the calibration curve plotted on the same day. The accuracy was calculated as mean percentage relative recovery by comparing the observed concentrations with nominal concentrations at each level of quality control. The precision at each level was evaluated as percentage relative standard deviation (\%RSD).

\section{Stability}

The stability of rasagiline in plasma was assessed at LQC and HQC levels. The stability at room temperature was evaluated by preparing and storing the six replicates of both QC levels at $25^{\circ} \mathrm{C}$ for $24 \mathrm{~h}$. For freeze and thaw stability, the concentration of rasagiline was determined in both QC levels $(n=6)$ after three freeze and thaw cycles with $24 \mathrm{~h}$ gap between each cycle. The long-term stability was assessed by storing the plasma samples of LQC \& HQC levels at $20^{\circ} \mathrm{C}$ for more than 3 months. For each set of stability evaluation, the concentration of rasagiline was determined against the curve plotted from freshly prepared standard samples.

\section{Recovery}

The absolute recovery of rasagiline from the drug spiked plasma across QC samples when compared with solvent equivalent samples was within $88.46-96.21 \%$ range, with \% RSD less than 4.14 at each of the concentration levels. High recovery value waives off the use of internal standard in the method and low \% RSD value shows that the solvent selected for the method was efficient.

\section{RESULTS}

\section{Developed method}

The run time of rasagiline was 10 min with a peak appearing at $7 \mathrm{~min}$ following optimization of mobile phase and HPLC conditions.

\section{Validation data}

\section{Selectivity}

The chromatograms of plasma samples spiked with $20 \mu \mathrm{g} / \mathrm{mL}$ and $0.5 \mu \mathrm{g} / \mathrm{mL}$ rasagiline were compared with the drug free plasma sample. Rasagiline peak appeared at $7 \mathrm{~min}$ in spiked samples (Figure 1, b \& c) while no peak was detectable at the same retention time in drug free plasma (Figure 1, a). Thus, the developed method is selective for rasagiline and no interference with plasma proteins was found.

\section{Linearity}

The calibration curves were constructed by plotting concentration of drug versus peak area. Linearity was determined through linear regression analysis and the least square regression method. It was measured over a concentration range of 0.5 to $20 \mu \mathrm{g} / \mathrm{mL}$. All plotted calibration curves were linear with coefficient of determination $r^{2} \geq 0.999$. The lowest level in calibration curve with acceptable accuracy and precision was $0.5 \mu \mathrm{g} / \mathrm{mL}$ (Table 1) and this is the lower limit of quantification (LLOQ) of our method.

\section{Accuracy and precision}

The percentage relative recovery for accuracy and relative standard deviation (RSD \%) for precision are shown in Table 2. The values for within run accuracy ranged from 94.8 to $110 \%$ while RSD was $\leq 3.99 \%$. Similarly, the results for between-run accuracy were 96.8 to $98.5 \%$ and RSD was $\leq 3.59 \%$. The results for all the quality control levels were within the acceptable criteria described by EMA guideline which is \pm 15 
$\%$ for accuracy and $\leq 15 \%$ for precision.
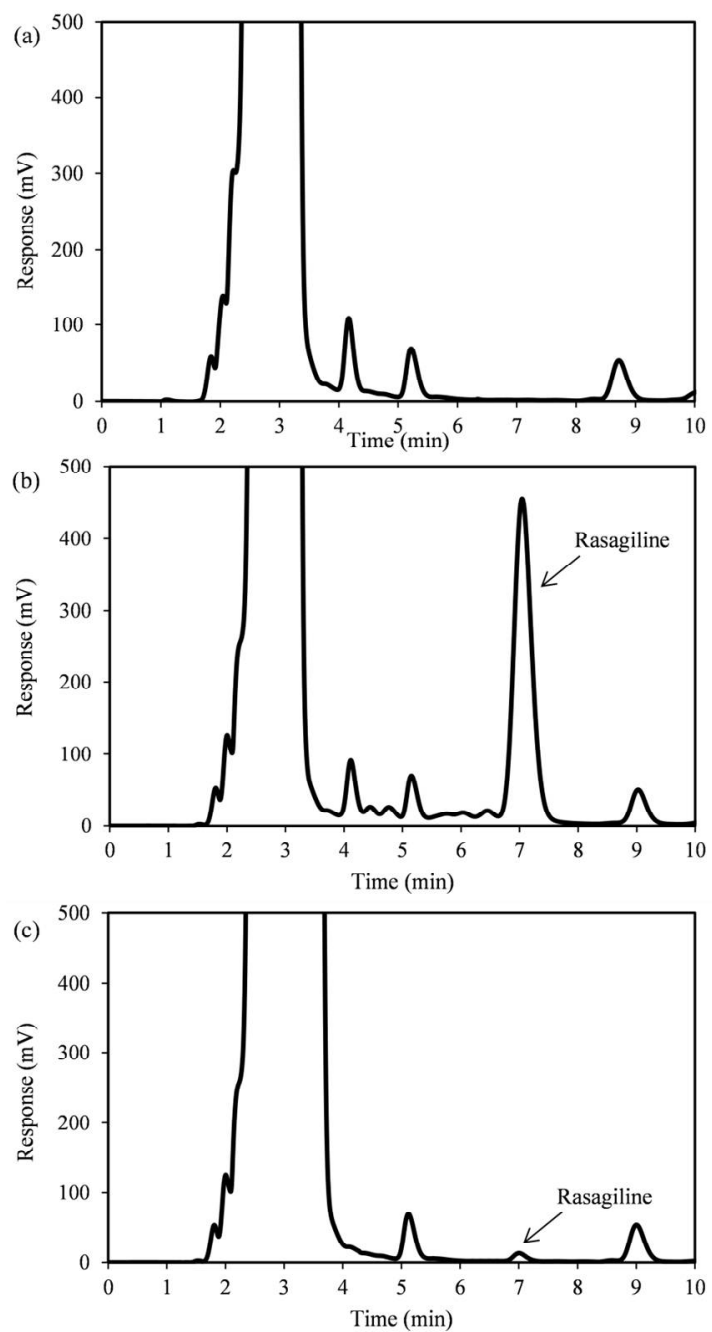

Figure 1: Chromatogram of (a) blank plasma, (b) plasma spiked with rasagiline $20 \mu \mathrm{g} / \mathrm{mL}$, and (c) $0.5 \mu \mathrm{g} / \mathrm{mL}$

\section{Stability}

The results for stability of rasagiline in plasma at HQC and LQC levels are shown in Table 3. Rasagiline was stable after four freeze-thaw cycles with mean relative recovery of 101.3 and $97.7 \%$ and the RSD of 1.30 and $0.90 \%$ for HQC and LQC, respectively.

The mean percentage relative recovery after storage of plasma samples at room temperature for 24 hours was 97.8 and $98.3 \%$ while RSD was 1.22 and $2.82 \%$ for HQC and LQC, respectively. Rasagiline was also stable after storage of plasma samples at $-20{ }^{\circ} \mathrm{C}$ for $>3$ months. The mean percentage relative recovery was 99.1 and $96.4 \%$ while RSD was 2.46 and $2.08 \%$ for HQC and LQC, respectively. The stability of rasagiline in plasma samples ensures that rasagiline samples can be analyzed after repeated freeze and thaw cycles and can also be stored at $-20^{\circ} \mathrm{C}$ for $>3$ months.

\section{Recovery}

The absolute recovery of rasagiline from the drug spiked plasma for HQC, MQC and LQC when compared with solvent equivalent samples are shown in table 4. The values of absolute recovery for HQC, MQC and LQC were 95.02, 93.16 and $91.44 \%$, respectively while \%RSD values were $\leq 3.18 \%$. The recovery of all the three levels of QC samples is > $90 \%$. High recovery value waives off the use of internal standard in the method and low \% RSD value shows that the solvent selected for the method is efficient. The data are presented in Table 3.

Table 1: Back calculated concentrations of rasagiline in calibration standard solutions $(n=6)$

\begin{tabular}{lcccccc}
\hline \multirow{2}{*}{ Back calculated conc } & \multicolumn{5}{c}{ Nominal Concentrations $(\boldsymbol{\mu g} / \mathbf{m L})$} \\
\cline { 2 - 6 } & $\mathbf{2 0}$ & $\mathbf{1 0}$ & $\mathbf{5}$ & $\mathbf{2}$ & $\mathbf{1}$ & $\mathbf{0 . 5}$ \\
\hline Mean \pm SD $(\mathrm{ng} / \mathrm{mL})$ & $20.1 \pm 0.37$ & $9.96 \pm 0.38$ & $4.97 \pm 0.37$ & $1.98 \pm 0.32$ & $1.06 \pm 0.07$ & $0.56 \pm 0.03$ \\
Recovery $(\%)$ & 100.5 & 99.8 & 99.7 & 98.9 & 105.6 & 109.4 \\
RSD $(\%)$ & 1.05 & 1.25 & 1.86 & 3.25 & 1.36 & 12.8 \\
\hline
\end{tabular}

Table 2: Accuracy and precision (within-run and between-run, $n=6)$ )

\begin{tabular}{lccc}
\hline Accuracy and precision & \multicolumn{3}{c}{ Nominal concentration $(\boldsymbol{\mu g} / \mathbf{m L})$} \\
\cline { 2 - 4 } & $\mathbf{1 5}(\boldsymbol{H Q C})$ & $\mathbf{6}(\mathbf{M Q C})$ & $\mathbf{0 . 7}(\mathbf{L Q C})$ \\
\hline Within-run $^{a}$ & & & \\
Mean $\pm S D(\mathrm{ng} / \mathrm{mL})$ & $14.2 \pm 0.23$ & $6.07 \pm 0.13$ & $0.77 \pm 0.06$ \\
Recovery $(\%)$ & 94.8 & 101.1 & 110.2 \\
RSD (\%) & 0.93 & 0.83 & 3.99 \\
Between-run & & & \\
Mean \pm SD $(\mathrm{ng} / \mathrm{mL})$ & $14.5 \pm 0.11$ & $5.81 \pm 0.06$ & $0.69 \pm 0.04$ \\
Recovery (\%) & 96.8 & 96.8 & 98.1 \\
RSD (\%) & 0.46 & 0.39 & 3.59 \\
\hline
\end{tabular}

${ }^{\mathrm{a}}$ Analyzed on same day; ${ }^{\mathrm{b}}$ analyzed on 6 different days 
Table 4: Rasagiline recovery from plasma and solvent in HQC, MQC and LQC $(n=6)$

\begin{tabular}{lccc}
\hline Recovery & \multicolumn{3}{c}{ Nominal concentration $(\boldsymbol{\mu g} / \mathbf{m L})$} \\
\cline { 2 - 4 } & $\mathbf{1 5}(\boldsymbol{H Q C})$ & $\mathbf{6}(\boldsymbol{M Q C})$ & $\mathbf{0 . 7}(\boldsymbol{L Q C})$ \\
\hline Plasma (mean \pm SD) & $14.2 \pm 0.24$ & $5.54 \pm 0.05$ & $0.68 \pm 0.028$ \\
Solvent (mean \pm SD) & $14.9 \pm 0.10$ & $5.95 \pm 0.05$ & $0.74 \pm 0.028$ \\
Recovery $(\%)$ & 95.02 & 93.16 & 91.44 \\
RSD $(\%)$ & 1.24 & 1.41 & 3.18 \\
\hline
\end{tabular}

Table 3: Stability of rasagiline in plasma samples $(\mathrm{n}=$ 6)

\begin{tabular}{|c|c|c|}
\hline \multirow[t]{2}{*}{ Stability } & \multicolumn{2}{|c|}{ Nominal concentration $(\mu \mathrm{g} / \mathrm{mL})$} \\
\hline & $15(H Q C)$ & $6(L Q C)$ \\
\hline \multicolumn{3}{|l|}{$\begin{array}{l}\text { Freeze-thaw } \\
\text { stability }^{a}\end{array}$} \\
\hline $\begin{array}{l}\text { Mean } \pm S D \\
(n g / m L)\end{array}$ & $15.01 \pm 0.02$ & $5.86 \pm 0.33$ \\
\hline Recovery (\%) & 101.3 & 97.7 \\
\hline RSD (\%) & 1.30 & 0.90 \\
\hline \multicolumn{3}{|l|}{$\begin{array}{l}\text { Stability at } \\
\text { room emp }\end{array}$} \\
\hline $\begin{array}{l}\text { Mean } \pm S D \\
(\mathrm{ng} / \mathrm{mL})\end{array}$ & $14.67 \pm 0.06$ & $5.90 \pm 0.30$ \\
\hline Recovery (\%) & 97.80 & 98.3 \\
\hline RSD (\%) & 1.22 & 2.82 \\
\hline \multicolumn{3}{|l|}{$\begin{array}{l}\text { Long-term } \\
\text { stability }^{c}\end{array}$} \\
\hline $\begin{array}{l}\text { Mean } \pm S D \\
(\mathrm{ng} / \mathrm{mL})\end{array}$ & $14.86 \pm 0.04$ & $5.78 \pm 0.61$ \\
\hline Recovery (\%) & 99.1 & 96.4 \\
\hline RSD (\%) & 2.46 & 2.08 \\
\hline
\end{tabular}

\section{DISCUSSION}

Different analytical procedures in terms of mobile phase composition, $\mathrm{pH}$, column selection and detectors have been adopted for the determination of rasagiline $[2,7,10,11]$. Among these methods some were developed by using expensive mass spectrometry technique $[7,11]$ few are reported for quantification of dosage form \& pharmaceutical preparations in chemical solvents [2,10]. An HPLC method with UV detection was reported for quantification of rasagiline from different plasma matrices and was applied for pharmacokinetic studies in rabbits [12]. Therefore to the best of our knowledge this is the first HPLC method with UV detector developed for quantification of rasagiline with LOQ $0.7 \mu \mathrm{g} / \mathrm{mL}$ in human plasma.

The retention time of 7 minutes was comparable with that reported earlier using an ODS column [17]. A shorter retention time (5.78 $\mathrm{min}$ ) has also been reported however, the ratio of acetonitrile was much higher $(60 \%)$ in that method [12] when compared to our method (45\%). More sensitive methods with LLOQ up to $5 \mathrm{pg} / \mathrm{mL}$ have been reported but utilize complex and expensive
LCMS techniques [7] which is difficult in the resource limited settings of Pakistan and other developing countries. The results for all the quality control levels were within the acceptable criteria described by EMA guideline which is \pm 15 $\%$ for accuracy and $\leq 15 \%$ for precision.

\section{CONCLUSION}

A new method has been developed and successfully validated for the determination of the concentration of rasagiline in human plasma. This HPLC method is simple, sensitive and reliable, and would be suitable for pharmacokinetic studies of rasagiline in humans.

\section{DECLARATIONS}

\section{Acknowledgement}

The authors are grateful to Searle Pharmaceutical, Karachi, Pakistan for providing rasagiline standard drug. Furthermore, we are also thankful to Ms Huma Rasheed for her guidance in the preparation of the manuscript.

\section{Conflict of interest}

The authors declare that no conflict of interest is associated with this study.

\section{Contribution of authors}

We declare that this work was done by all the authors stated below in this article and all liabilities pertaining to claims relating to the content of this article will be borne by the authors. Dr. Rabiea Bilal conceived and designed the study, collected data and manuscript writing.

\section{REFERENCES}

1. Leegwater-Kim J, Bortan E. The role of rasagiline in the treatment of Parkinson's disease. Clin Interv Aging 2010; 5: 149-156.

2. Reddy PS, Sudhakar K, Kumar N. Development and validation of a stability-indicating RP-HPLC method for the simultaneous estimation of process related impurities and degradation products of rasagiline

Trop J Pharm Res, November 2018; 17(11): 2247 
mesylate in pharmaceutical formulation. J Chromatogr Sci 2013; 51(3): 242-249

3. Olanow CW, Kieburtz K, Leinonen M, Elmer L, Giladi N, Hauser RA, Klepiskaya OS, Kreitzman DL, Lew MF, Russell DS, et al. A randomized trial of a low-dose Rasagiline and Pramipexole combination (P2B001) in early Parkinson's disease. Mov Disord 2017; 32(5): 783789.

4. Bar-Am O, Amit T, Youdim MB. Contrasting neuroprotective and neurotoxic actions of respective metabolites of anti-Parkinson drugs rasagiline and selegiline. Neurosci Lett 2004; 355(3): 169-172.

5. Bar-Am O, Yogev-Falach $M$, Amit T, Sagi Y, Youdim MB. Regulation of protein kinase $C$ by the anti-Parkinson drug, MAO-B inhibitor, rasagiline and its derivatives, in vivo. J Neurochem 2004; 89(5): 1119-1125.

6. Hubalek F, Binda C, Li M, Herzig Y, Sterling J, Youdim $M B$, Mattevi A, Edmondson DE. Inactivation of purified human recombinant monoamine oxidases $A$ and $B$ by rasagiline and its analogues. J Med Chem 2004; 47(7): 1760-1766.

7. Konda RK, Chandu BR, Challa Br, Kothapalli CB. Bioanalytical method development and validation of Rasagiline by high performance liquid chromatography tandem mass spectrometry detection and its application to pharmacokinetic study. J Pharm Anal 2012; 2(5): 342349.

8. Thorn CF, Aklillu E, Klein TE, Altman RB. PharmGKB summary: very important pharmacogene information for CYP1A2. Pharmacogenet Genomics 2012; 22(1): 73-77.

9. Van der Weide J, Steijns LS, Van Weelden MJ. The effect of smoking and cytochrome P450 CYP1A2 genetic polymorphism on clozapine clearance and dose requirement. Pharmacogenetics 2003; 13(3): 169-172.

10. Fernandez M, Barcia E, Negro S. Development and validation of a reverse phase liquid chromatography method for the quantification of rasagiline mesylate in biodegradable PLGA microspheres. J Pharm Biomed Anal 2009; 49(5): 1185-1191.

11. Ma J, Chen $X$, Duan $X$, Deng $P$, Wang $H$, Zhong $D$. Validated LC-MS/MS method for quantitative determination of rasagiline in human plasma and its application to a pharmacokinetic study. J Chromatogr $B$ Analyt Technol Biomed Life Sci 2008; 873(2): 203-208.

12. Ravi PR, Aditya N, Cherian L, Patil S. LC method for determination of rasagiline mesylate in different plasma matrices and its application to oral pharmacokinetic study in rabbits. J Chromatogr Sci 2013; 51(1): 1-7.

13. Wang $T$, Yang $L$, Hua $J$, Xie $H$, Jiang $X$, Wang $L$. Simultaneous bioanalysis of rasagiline and its major metabolites in human plasma by LC-MS/MS: Application to a clinical pharmacokinetic study. J Pharm Biomed Anal 2016; 125: 280-285.

14. Dompreh A, Tang X, Zhou J, Yang H, Topletz A, AduAhwireng $E$, Antwi S, Enimil A, Langaee T, Peloquin CA, et al. Effect of Genetic Variation of NAT2 on Isoniazid and SLCO1B1 and CES2 on Rifampin Pharmacokinetics in Ghanaian Children with Tuberculosis. Antimicrob Agents Chemother 2018; 62(3): 1-11.

15. Naidoo A, Ramsuran V, Chirehwa $M$, Denti $P$, Mclleron $H$, Naidoo K, Yende-Zuma N, Singh R, Ngcapu $S$, Chaudhry $M$, et al. Effect of genetic variation in UGT1A and $A B C B 1$ on moxifloxacin pharmacokinetics in South African patients with tuberculosis. Pharmacogenomics $J$ 2018; 19(1): 17-29.

16. European Medicines Agency. Guideline on bioanalytical method validation, 2011 [cited 2016 Mar 04]. Available from:

http://www.ema.europa.eu/docs/en_GB/document_librar y/Scientific_guideline/2011/08/WC500109686.pdf.

17. Bukka R, Prakasam K. HPLC estimation of rasagiline mesylate during buccal permeation studies. Int. J. Pharm. Sci. Rev. Res 2012; 16(1): 115-119. 